\title{
Assessment of IgG antibodies to Pseudomonas aeruginosa in patients with cystic fibrosis by an enzyme-linked immunosorbent assay (ELISA)
}

\author{
Renan Marrichi Mauch ${ }^{1}$, Cláudio Lúcio Rossi ${ }^{1}$, José Dirceu Ribeiro², Antônio Fernando Ribeiro², \\ Marcos Tadeu Nolasco da Silva ${ }^{2}$ and Carlos Emílio Levy ${ }^{1 *}$
}

\begin{abstract}
Background: The usefulness of serological tests for detection of $P$. aeruginosa pulmonary infection in cystic fibrosis (CF) is controversial. Here, we assessed the value of detecting anti-P. aeruginosa IgG by a quantitative enzyme-linked immunosorbent assay (ELISA) for identification of $P$. aeruginosa infection in patients with cystic fibrosis.

Methods: Serum concentrations of anti-P. aeruginosa lgG were assessed in 117 CF patients classified according to their P. aeruginosa colonization/infection status (never colonized; free of infection; intermittently colonized and chronically infected) and in 53 healthy subjects by the ELISA test standardized with the St-Ag:1-17 antigen.

Results: The rate of IgG seropositivity and the median of $\lg G$ concentrations of this antibody in patients chronically infected were significantly higher than those found in the other CF groups and in the healthy control group.
\end{abstract}

Conclusion: Detection of anti-P. aeruginosa lgG can be an useful tool for identification of $P$. aeruginosa chronic infection in patients with CF.

Virtual Slides: The virtual slide(s) for this article can be found here: http://www.diagnosticpathology.diagnomx.eu/vs/ 13000_2014_158

Keywords: Pseudomonas aeruginosa, Cystic Fibrosis, Serology, ELISA

\section{Background}

Cystic fibrosis (CF) is the most common hereditary disease in the Caucasian population, with a wide range of clinical and genetic variants [1]. The genetic defect occurs in the $\mathrm{CF}$ transmembrane conductance regulator (CFTR) gene, which codes for a protein that regulates the transport of electrolytes across epithelial cell membranes. Mutations in the CFTR gene affect sodium and chloride ion transport, resulting in the disruption of the ionic composition and volume of airway surface fluid. This fluid is normally thin to allow removal of inhaled microorganisms via ciliary action; however, in the presence of CFTR mutations, it increases in volume and becomes viscous, clogging the airways. As a result, microorganisms

\footnotetext{
* Correspondence: celevy@fcm.unicamp.br

${ }^{1}$ Department of Clinical Pathology, Faculty of Medical Sciences, State University of Campinas, Rua Alexander Fleming 105, Block FCM 12, 2nd floor, Postal code: 13083-881 Campinas, SP, Brazil

Full list of author information is available at the end of the article
}

entering the distal airways are not cleared and can cause chronic infections with progressive inflammation and respiratory insufficiency [2]. The clinical outcomes are similar to those found in diffuse panbronchiolitis, chronic obstructive pulmonary disease and idiopatic pulmonary fibrosis [3-5].

Pseudomonas aeruginosa is an important pathogen in nosocomial and opportunistic infections due to its high intrinsic resistance to antibiotics and ability to develop multidrug resistance, which lead to serious therapeutic problems [6]. $P$. aeruginosa is the most important and frequent pathogen in CF patients $[2,7,8]$, responsible for elevated morbidity and mortality [1-3]. When chronic $P$. aeruginosa pulmonary infection is established, this bacterium is practically impossible to be eradicated; however, the elimination from the airways is possible by early intervention with antibiotic therapy, as soon as the pathogen settles in the organism. Thus, the prompt 
treatment is recommended and may delay the progression of the pulmonary disease [9].

Detection of $P$. aeruginosa in the diagnostic routine is made mostly through sputum culture; however, many patients - especially children under seven years old- are incapable of producing an expectorated sputum specimen. Bronchoalveolar lavage (BAL) is an option, but is invasive and usually employed only when there is a compelling reason to obtain a respiratory sample and other approaches have failed $[10,11]$. More superficial samples include oropharyngeal (OP) and cough swab [12,13]; however, the frequent insufficient samples obtained through swabs can lead to false negative results and recent reports have shown that OP swabs poorly reflect the lung microbiota $[13,14]$. The difficulty in obtaining representative respiratory specimens from the airways of infants and children indicates the need for the use of methods that can complement or be an alternative to microbiological culture [15].

Serological tests have been used to assist the identification of $P$. aeruginosa infection in CF patients, particularly in patients who do not produce sputum. Some reports also suggest that serological tests may help in the differentiation between intermittent colonization and chronic infection $[16,17]$.

The diagnostic value of serological tests for detection of $P$. aeruginosa infection in cystic fibrosis is controversial, with large variations in the sensitivity and specificity values [18]. The aim of the present study was to assess the value of detecting anti- $P$. aeruginosa IgG by a quantitative enzymelinked immunosorbent assay (ELISA) for identification of $P$. aeruginosa infection in patients with cystic fibrosis.

\section{Methods}

\section{Patients, controls and serum samples}

Serum samples were obtained from 117 patients with confirmed CF diagnosis [19-21] who attended the cystic fibrosis ambulatory of the University Hospital, State University of Campinas, São Paulo, Brazil. Of these 117 patients, 35 (22 male, 13 female; median age $=3.0$ years $)$ had never been colonized with $P$. aeruginosa, 27 (8 male, 19 female; median age $=8.2$ years) were free of infection, 24 (16 male, 8 female; median age $=9.0$ years $)$ were intermittently colonized and 31 ( 17 male, 14 female; median age $=14.7$ years) were chronically infected by the pathogen. Fifty-three serum samples from pediatric patients and university students (32 male, 21 female; median age $=9.7$ years) without $\mathrm{CF}$ and no previous history of $P$. aeruginosa infection were used as controls.

\section{Bacteriology and classification of the patients according to microbiological culture}

The lower airway secretion was obtained by sputum expectoration in an universal sterile container. In case of non-expectorating patients, secretion of the upper airways was collected with OP swab and transported to the laboratory within $3 \mathrm{~h}$. Microbiological culture and identification were performed according to methodology previously described [7]. To classify the CF patients according to their $P$. aeruginosa colonization/infection status, we used an adaptation of the Leeds criteria [8], basing on the results of 12 last respiratory microbiological cultures prior to the blood sample collection, considering cultures were made every three month. Thus, we classified the patients as: (1) chronic infection, when $\geq 50 \%$ of the cultures were positive to $P$. aeruginosa, (2) intermittent colonization, when $<50 \%$ of the cultures were positive to $P$. aeruginosa, (3) free of infection, when the last 12 cultures were negative to $P$. aeruginosa with a previous positive culture and (4) never colonized, when $P$. aeruginosa was never isolated in microbiological culture.

\section{Determination of optimum assay conditions}

The ELISA was standardized by using excess amounts of all reagents except the one being tested. A pooled human standard antiserum (Statens Serum Institute, Copenhagen, Denmark) diluted 1:200 was arbitrarily designed as having 1000 activity antibody units per milliliter $(\mathrm{U} / \mathrm{mL})$. Artificial serum standards containing different antibody concentrations $(\mathrm{U} / \mathrm{mL})$ were prepared by diluting this antiserum with phosphate buffered saline containing 0.1\% Tween 20 (PBS-T). For the St-Ag:1-17 antigen (Statens Serum Institute, Copenhagen, Denmark) and conjugate (peroxidase-labeled rabbit anti-human IgG, Dako, Glostrup, Denmark) titrations, dilutions from 1:250 to 1:64000 were tested. The linearity of substrate conversion was assayed at time intervals from 1 to $60 \mathrm{~min}$, using serum standards containing 25 and $100 \mathrm{U} / \mathrm{mL}$.

\section{ELISA for detection antibodies to P. aeruginosa}

The antigen preparation diluted $1: 2000$ in $0.1 \mathrm{M}$ carbonate-bicarbonate buffer, $\mathrm{pH}$ 9.5, was used to sensitize wells of Maxisorp ELISA plates (Thermo Fisher, Waltham, MA, United States). After sensitization for $1 \mathrm{~h}$ $30 \mathrm{~min}$ at room temperature (RT), the wells were washed three times with PBS-T, after which $100 \mu \mathrm{l}$ of $0.1 \%$ bovine serum albumin in $0.1 \%$ PBS-T were added to the wells. After incubation for $1 \mathrm{~h}$ at RT, the wells were washed twice with PBS-T and $100 \mu \mathrm{l}$ of each serum sample diluted 1:800 in PBS-T were added in triplicate to the wells. After a further $1 \mathrm{~h}$ incubation at RT and washing three times with PBS-T, $100 \mu \mathrm{l}$ of conjugate diluted 1:4000 in PBS-T were added to the wells and the plates were incubated for $1 \mathrm{~h}$ at RT. After incubation and five washes with PBS-T, $100 \mu \mathrm{l}$ of substrate system (0.42 $\mathrm{mM}$ tetramethylbenzidine and $1.42 \mathrm{mM} \mathrm{H}_{2} \mathrm{O}_{2}$ in $0.1 \mathrm{M}$ sodium acetate/acetic acid buffer, $\mathrm{pH}$ 5.5) were added to the wells. Ten minutes after the addition of the 
substrate, $100 \mu \mathrm{l}$ of $2 \mathrm{~N} \mathrm{H}_{2} \mathrm{SO}_{4}$ were added to each well to stop the color reaction and the resulting absorbances were read at 450 and $630 \mathrm{~nm}$ in an ELISA reader (Labsystems, Helsinki, Finland). A negative control and artificial positive serum standards containing different concentrations of the antibody were included in each ELISA plate. The final optical density for each well was determined by subtracting the mean optical density of two antigen controls in the corresponding plate. All serum samples and positive standards were tested in triplicate and the mean activity determined. A standard curve was used to translate optical density readings of each serum specimen into $\mathrm{U} / \mathrm{mL}$.

\section{Definition of the results status}

The cut-off value for the assay was determined by a receiver operating characteristic (ROC) curve, using the ELISA results obtained with CF patients chronically infected with $P$. aeruginosa and healthy subjects. Analyzing the results obtained with different dilutions of serum samples from chronically infected patients, a variation of $5 \%$ was applied to the cut-off value to define three areas of test results - positive, negative and a grey zone between them.

\section{Statistical analyses}

The Chi-square test was used to compare the rates of IgG seropositivity among the CF patients and healthy controls simultaneously; a confidence interval of $95 \%$ was adopted. With respect to the medians of the antibody concentrations, the Mann-Whitney test and the Kruskal Wallis test were used for comparisons between two groups and more than two groups, respectively. The Spearman test was used to identify correlation between antibody levels and age of CF patients chronically infected with $P$. aeruginosa. In all tests, a $p$ value $<0.05$ was considered statistically significant. The statistical analyses were done using SAS (Statistical Analysis System) for Windows version 9.2 (SAS Inc., Cary, NC, United States).

\section{Results}

Titration experiments defined 1:2000 and 1:4000 as the optimal dilutions of antigen and conjugate, respectively. The linearity studies showed that the substrate conversion rates were linear for at least $10 \mathrm{~min}$ for standards containing 25 and $100 \mathrm{U} / \mathrm{mL}$. The cut-off value for specific $P$. aeruginosa-IgG antibodies determined by the ROC curve was $14.57 \mathrm{U} / \mathrm{mL}$. Applying a $5 \%$ of variation to this cut-off, negative, grey zone, and positive test results were defined as $<13.8 \mathrm{U} / \mathrm{mL}, 13.8$ to $15.3 \mathrm{U} / \mathrm{mL}$ and $>15.3 \mathrm{U} / \mathrm{mL}$.

A total of 170 serum samples, 117 from CF patients and 53 from healthy subjects, were assayed for anti- $P$. aeruginosa IgG. Table 1 presents the demographic characteristics of CF patients and healthy controls, as well as the rate of positivity for anti-P. aeruginosa IgG in all groups. Positive results were found in $1 / 35(2.9 \%)$ of the CF patients never colonized, in 3/27 (11.1\%) of patients free of infection, in $8 / 24$ (33.3\%) of patients intermittently colonized, in 30/31 (96.8\%) of patients chronically infected and in one healthy control (1.9\%). The rate of IgG seropositivity in patients chronically infected was significantly higher than those found in the other $\mathrm{CF}$ groups and in the healthy control group $(\mathrm{p}<0.0001)$. The rate of IgG seropositivity in intermittently colonized CF patients was significantly higher than those found in $\mathrm{CF}$ patients never colonized and in the healthy controls $(\mathrm{p}<$ 0.001 ). Figure 1 shows the medians of IgG concentrations $(\mathrm{U} / \mathrm{mL})$ in CF patients and healthy controls. The median of IgG concentration in patients chronically infected was significantly higher than those found in the other $\mathrm{CF}$ groups and in the healthy control group $(\mathrm{p}<0.0001)$. No significant differences were found between healthy controls and CF patients free of infection $(p=0.232)$, between healthy controls and CF patients never colonized $(p=0.062)$ and between CF patients free of infection and those with intermittent colonization $(\mathrm{p}=0.064)$. A positive correlation between antibody levels and age was found in chronically infected CF patients by the Spearman test $(\mathrm{r}=0.40 ; \mathrm{p}<0.01)$.

\section{Discussion}

The antibody response to $P$. aeruginosa in cystic fibrosis has been considered a marker of chronic infection, inflammation and tissue damage [22,23]. In the last three decades, several studies have shown the potential of antibody detection for early diagnosis of $P$. aeruginosa pulmonary infection [15-18] in order to initiate the early eradication therapy [23].

The standardization of a quantitative ELISA for detection of specific antibodies requires that the concentrations of all reagents and reaction times be optimized. It is important the measurement of enzymatic activity during the linear part of the reaction, when substrate concentration is much higher than enzyme concentration. The standardization of the assay involves the use of a positive standard from which a standard curve is prepared and included in each ELISA plate, with the reactivity of the samples being tested determined from the standard curve. The utilization of a standard curve in every reaction plate reduce the variability of the assay $[24,25]$.

In our study, the rate of anti-P.aeruginosa IgG seropositivity and the concentration of this antibody were significantly higher in the patients chronically infected than those in the other CF groups, corroborating previous studies that showed high frequency of detection and elevated levels of this antibody in this phase of infection $[18,26,27]$. One serum sample from a CF patient with chronic infection by $P$. aeruginosa who was under 
Table 1 Gender, age and detection of anti-P. aeruginosa IgG in patients with cystic fibrosis and in healthy controls

\begin{tabular}{|c|c|c|c|c|c|}
\hline \multirow{2}{*}{ Parameters } & \multicolumn{5}{|l|}{ Subject groups } \\
\hline & CF chronic infection & CF intermittent colonization & CF free of infection & CF never colonized & Healthy controls \\
\hline Number of subjects & 31 & 24 & 27 & 35 & 53 \\
\hline Gender (M/F) & $17 / 14$ & $16 / 8$ & $8 / 19$ & $22 / 13$ & $32 / 21$ \\
\hline Median age - years (range) & $14.7(3-30)$ & $9.0(1.6-16)$ & $8.2(3-25)$ & $3.0(0.16-26)$ & $9.7(0.16-30)$ \\
\hline$\%$ IgG seropositivity [C.I. 95\%] & $96.8(81.5-99.8)$ & $33.3(16.4-55.3)$ & $11.1(2.9-30.3)$ & $2.9(0.2-16.6)$ & $1.89(0.1-11.4)$ \\
\hline
\end{tabular}

The rate of IgG seropositivity in patients chronically infected was significantly higher than those found in the other CF groups and in the healthy control group $(p<0.0001)$. The rate of $\mathrm{IgG}$ seropositivity in intermittent colonized patients was significantly higher than those found in CF patients never colonized and in the healthy controls $(p<0.001)$.

antibiotic therapy gave a negative serological result for the pathogen. Some studies have shown that antibiotic treatment regimens may result in decrease of the antibody levels to $P$. aeruginosa [28-30].

A healthy control with no history of $P$. aeruginosa infection showed a positive serology to the pathogen. Previous reports showed the occurrence of false negative results [22,31-33]. Since $P$. aeruginosa is an environmental pathogen, it is possible that this healthy control have got in contact with this bacterium in a period next to the study, leading to a transient antibody response $[23,26]$. Some authors have also shown that the StAg:1-17 preparation contains antigens which are crossreactive with other gram-negative bacteria, including Haemophilus influenzae [17,28], which is a common microorganism in the respiratory tract of healthy children and adults. Høiby et al. [22] and Pedersen et al. [33] observed, in healthy controls, an increase in the antibody levels over the age. They attribute these facts to the normal occurrence of cross reactions with other pathogens and

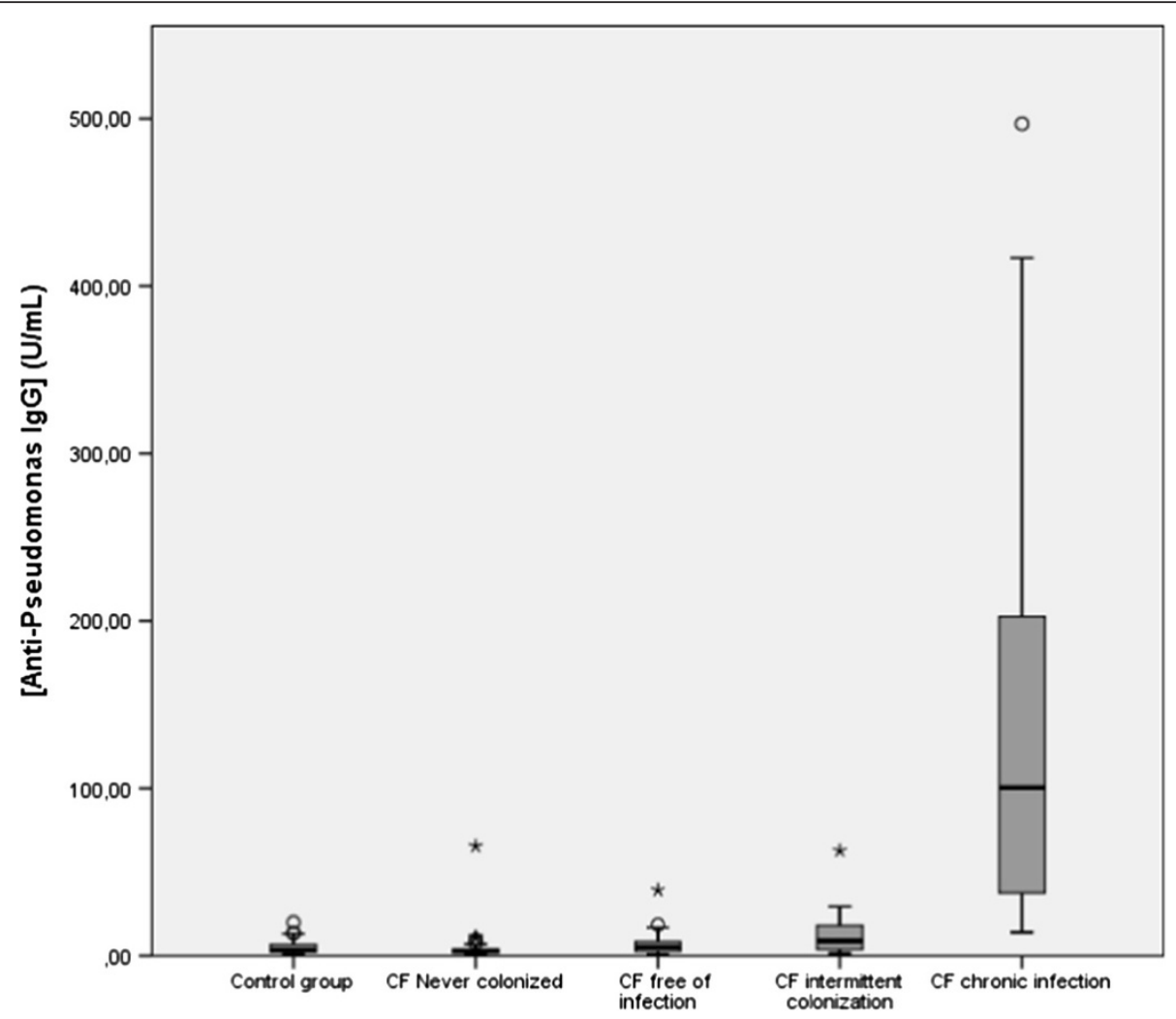

Figure 1 Serum concentrations of anti- $P$. aeruginosa $\operatorname{lgG}(\mathrm{U} / \mathrm{mL})$ in patients classified according to their $P$. aeruginosa colonization/ infection status and in healthy controls. The median of IgG concentration in patients chronically infected was significantly higher than those found in the other CF groups and in the healthy controls $(p<0,0001)$. No statistically significant differences were found between CF patients intermittently colonized and free of infection, between CF patients free of infection and the control group and between CF patients never colonized and the control group. 
to a possible acquired immunity over time, after patient contact with $P$. aeruginosa.

It has been known for many years that chronic $P$. aeruginosa infection is preceded by an intermittent colonization with the pathogen and previous reports showed an overlap in the antibody levels between chronically infected and intermittent colonized CF patients $[16,26,28]$. In the present study, we did not find statistical difference in the antibody titers between the intermittently colonized and the free of infection group. Indeed, the majority (66.7\%) of intermittently colonized patients had negative serology to $P$. aeruginosa; however, it is well known that $P$. aeruginosa isolation in respiratory samples not necessarily indicates infection, unless there is a specific humoral response $[8,34]$. In some patients, the colonization can persist for 1 to 2 years without eliciting an humoral immune response [33], which can be due to the presence of transient or non pathogenic strains, to the inadequate immune response to the pathogen [28], or even to the adequate immune response of the patient through secretory IgA $[23,28]$. Besides, there is a great interchange of patients between these two groups when longitudinal microbiological data are observed [26]. On the other hand, the positive antibody levels of $33.3 \%$ of the intermittently colonized patients in the present report may suggest a change in the colonization/ infection status for chronically infected [16,17]. These results draw attention to limitations in the Leeds criteria for definition of colonization and infection status [8], which are based solely on microbiological cultures. Serology results, in conjunction with more frequent respiratory cultures, can play an important role in elaborating a better definition for colonization and infection, mainly for patients classified as free of infection and intermittently colonized $[16,17,26,35]$.

Among the CF patients with negative microbiological respiratory culture, the rate of seropositivity was $2.9 \%$ and $11.1 \%$ in the never colonized group and the free of infection group, respectively. Such findings may suggest limitations in respiratory culture, which may not reflect the lung microbiota $[11,13,14]$, or even recurrent infection $[27,34]$. Many of these patients are not sputum producers, making more difficult to obtain representative respiratory samples, which may lead to false negative results. So, these groups constitute an important focus of interest for detection of serum anti-Pseudomonas antibodies [29].

A large variation in the performances of immunological assays used for the diagnosis of $P$. aeruginosa infection in CF patients has been observed [18], which is expected and is related to several factors including the antigen chosen, the criteria used for selection of the patients and healthy controls, the criteria adopted for classification of the colonization/infection status, the immune status of the patients at time of blood collection, the antibiotic treatment regimen, the intrinsic properties of the serological methods used for antibody detection, the antigen preparation, the lack of an appropriate reference standard and the method for calculating the cut-off value $[18,30,36]$. Here, we considered that culture results of one year prior to the serological analysis were not enough to provide a consistent classification of $P$. aeruginosa colonization/infection status. So, we used the 12 last culture results, seeking to optimize this classification. For classification according to serological results, we fixed negative and positive cut-off values through a ROC analysis, based on the results of a healthy population. This may help to avoid bias when determining the accuracy of the method [30,36]. The St-Ag:1-17 antigen was chosen by the fact of being a commercialized antigen; besides, the studies with the St-Ag:1-17 has been continuous over the last 30 years. Other antigens, like exotoxin $\mathrm{A}$, elastase and alkaline protease are quorum-sensing regulated antigens [17] and require a higher bacterial load to elicit the immune response. Since St-Ag:1-17 constitutes a pool of 64 antigens from 17 different $P$. aeruginosa serotypes, the immune response is earlier in relation to these other antigens $[17,23]$.

\section{Conclusions}

This report has the limitations of a cross-sectional study. Since that only one serum sample was obtained from each patient, we could not take further conclusions. Longitudinal reports have demonstrated the capacity of serology to detect $P$. aeruginosa infection until three years before microbiological culture [18]. Future protocols based in longitudinal studies in our laboratory should verify the importance of our findings. Besides, other diagnostic resources must be evaluated, like real-time PCR of respiratory samples, culture of paranasal sinuses secretions, the humoral response to other antigens and the secretory IgA response. Overall, the results of the present study show that the ELISA for detection of anti- $P$. aeruginosa IgG can be an useful tool for identification of $P$. aeruginosa chronic infection in patients with cystic fibrosis.

\section{Ethical approval}

The study was approved by the Ethics Committee (reference number: 719/2009) of the Faculty of Medical Sciences, State University of Campinas, in accordance with the resolutions of the Brazilian Ethics Committee.

\footnotetext{
Abbreviations

BAL: Bronchoalveolar lavage; CF: Cystic fibrosis; OP swab: Oropharyngeal swab; ELISA: Enzyme-linked immunosorbent assay; PCR: Polymerase chain reaction; PBS-T: Phosphate buffered saline containing 0.1\% tween 20; RT: Room temperature; ROC: Receiver operating characteristics; St-Ag:1-17: Standard pooled antigen (17 different $P$. aeruginosa serotypes); $\mathrm{U} / \mathrm{mL}$ : Activity antibody units per milliliter.
}

Competing interests

The authors declare they have no competing interests. 


\section{Authors' contributions}

RMM: collected the patients' samples, carried out the immunoassays and drafted the manuscript. CLR: have made substantial contributions in the analyses and interpretation of data and have been involved in drafting the manuscript and revising it critically for important intellectual content. JDR: have been involved in revising the manuscript critically for important intellectual content and have made substantial contributions to acquisition of data. AFR: have made substantial contributions to acquisition of data. MTNS: participated in the design of the study and helped to draft the manuscript. CEL: participated in the design of the study and coordination and have given final approval if the version to be published. All authors read and approved the final manuscript.

\section{Financial support}

This research was supported by CAPES (Coordenação de Aperfeiçoamento de Pessoal de Nível Superior) - Federal Government, Brazil - and FAEPEX (Fundo de Apoio ao Ensino, Pesquisa e Extensão) - State University of Campinas, Brazil.

\section{Author details}

${ }^{1}$ Department of Clinical Pathology, Faculty of Medical Sciences, State University of Campinas, Rua Alexander Fleming 105, Block FCM 12, 2nd floor, Postal code: 13083-881 Campinas, SP, Brazil. ${ }^{2}$ Department of Pediatrics, Faculty of Medical Sciences, State University of Campinas, Campinas SP, Brazil.

Received: 4 June 2014 Accepted: 31 July 2014

Published: 22 August 2014

\section{References}

1. Gonçalves AC, Marson FAL, Mendonça RMH, Ribeiro JD, Ribeiro AF, Paschoal IA, Levy CE: Saliva as a potential tool for cystic fibrosis diagnosis. Diagn Pathol 2013, 8:46.

2. Kiska DL, Riddell SW: Practical laboratory aspects of Cystic Fibrosis microbiology: an Update Part I. Clin Microbiol Newslett 2012, 34(Suppl 4):27-31.

3. Ginori A, Barone A, Bennett D, Butorano MAGM, Mastrougiulio MG, Fossi A, Rottoli P, Spina D: Diffuse panbronchiolitis in a patient with common variable immunodeficiency: a casual association or a pathogenic correlation? Diagn Pathol 2014, 9:12.

4. Goldman T, Kähler D, Schultz H, Abdullah M, Lang DS, Stellmacher F, Vollmer E: On the significance of Surfactant Protein-A within the human lungs. Diagn Pathol 2009, 4:8

5. Nagata N, Kitasato Y, Wakamatsu K, Kawabata M, Fukushima K, Kajiki A, Kitahara Y, Watanabe K: Prognostic value of immunohistochemical surfactant protein A expression in regenerative/hyperplasic alveolar epithelial cells in idiopathic intersticial pneumonias. Diagn Pathol 2011, 6:25.

6. Hammami S, Boutiba-Ben Boubaker I, Ghozzi R, Saidani M, Amine S, Ben RS: Nosocomial outbreak of imipenem-resistant Pseudomonas aeruginosa producing VIM- 2 metallo- $\beta$-lactamase in a kidney transplantation unit. Diagn Pathol 2011, 6:106.

7. Gilligan PH, Kiska DL, Appleman MD: Cystic fibrosis microbiology. In Cumulative techniques and procedures in clinical microbiology. Edited by Appleman MD. Washington, DC: ASM Press; 2006:1-36.

8. Lee TWR, Brownlee KG, Conway SP, Denton M, Littlewood JM: Evaluation of a definition for chronic Pseudomonas aeruginosa infection in cystic fibrosis patients. J Cyst Fibros 2003, 2(Suppl 1):29-34.

9. Taccetti G, Bianchini E, Cariani L, Buzzetti R, Constantini D, Trevisan F, Italian Group for P. aeruginosa Eradication in Cystic Fibrosis, Zavataro L, Campana S: Early antibiotic treatment for Pseudomonas aeruginosa eradication in patients with Cystic Fibrosis: a randomized multicenter study comparing two protocols. Thorax 2012, 67:853-859.

10. Tramper-Standers GA, van der Ent CK, Wolfs TFW: Detection of Pseudomonas aeruginosa in patients with cystic fibrosis. J Cyst Fibros 2005, 4:37-43.

11. Equi AC, Pike SE, Davies J, Bush A: Use of cough swabs in a cystic fibrosis clinic. Arch Dis Child 2001, 85(Suppl 5):438-439.

12. Rosenfeld M, Emerson J, Accurso F, Armstrong D, Castile R, Grinwood K, Hiatt P, McCoy K, McNamara S, Ramsey B, Wagener J: Diagnostic accuracy of oropharyngeal cultures in infants and young children with cystic fibrosis. Pediatr Pulmonol 1999, 28:321-328.

13. Burns JL, Rolain JM: Culture-based diagnostic microbiology in cystic fibrosis: Can we simplify the complexity? J Cyst Fibros 2014, 13:1-9.

14. Goddard AF, Staudinger BJ, Dowd SE, Joshi-Datar A, Wolcott RD, Aitken ML, Fligner CL, Singh PK: Direct sampling of cystic fibrosis lungs indicates that DNA-based analyses of upper-airway specimens can misrepresent lung microbiota. Proc Natl Acad Sci U S A 2012, 109:13769-13774.

15. Da Silva Filho LVF, Tateno AF, Martins KM, Azzuz Chernishev AC, Garcia DO, Haug M, Meisner C, Rodrigues JC, Döring G: The combination of PCR and serology increases the diagnosis of Pseudomonas aeruginosa colonization/infection in cystic fibrosis. Pediatr Pulmonol 2007, 42(Suppl 10):938-944.

16. Pressler T, Frederiksen B, Skov M, Garred P, Koch C, Høiby N: Early rise of anti-Pseudomonas antibodies and a mucoid phenotype of Pseudomonas aeruginosa are risk factors for development of chronic lung infection- A case control study. J Cyst Fibros 2006, 5:9-15.

17. Pressler T, Karpati F, Granström M, Knudsen PK, Lindbald A, Hjelte L, Olesen HV, Meyer P, Høiby N: Scandinavian CF Study Consortium. Diagnostic significance of mesuraments of specific IgG antibodies to Pseudomonas aeruginosa by three different serological methods. J Cyst Fibros 2009, 8:37-42.

18. Mauch RM, Levy CE: Serum antibodies to Pseudomonas aeruginosa in cystic fibrosis: a systematic review. J Cyst Fibros. in press.

19. De Boeck K, Derichs N, Fajac I, de Jonge HR, Bronsveld I, Sermet I, Vermeulen F, Sheppard DN, Cuppens H, Hug M, Melotti P, Middleton PG, Wilschanski M, ECFS Diagnostic Network Working Group, EuroCareCF WP3 Group on CF diagnosis: New clinical diagnostic procedures for cystic fibrosis in Europe. J Cyst Fibros 2011, 10(Suppl 2):s53-s66.

20. Farrell PM, Rosenstein BJ, White TB, Accurso FJ, Castellani C, Cutting GR, Durie PR, Legrys VA, Massie J, Parad RB, Rock MJ, Campbell PW III, Cystic Fibrosis Foundation: Guidelines for Diagnosis of Cystic Fibrosis in Newborns through Older Adults: Cystic Fibrosis Foundation Consensus Report. J Pediatr 2008, 153(Suppl 3):S4-s14.

21. Ooi CY, Dupuis A, Elis L, Jarvi K: Comparing the American and European diagnostic guidelines for cystic fibrosis: same disease, different language? Thorax 2012, 67:618-624.

22. Høiby N, Flensborg EW, Beck B, Friis B, Jacobsen SV, Jacobsen L: Pseudomonas aeruginosa in cystic fibrosis. Diagnostic and prognostic significance of Pseudomonas aeruginosa precipitins determined by means of crossed immunoelectrophoresis. Scand J Respir Dis 1977, 58:65-79.

23. Doring G, Høiby N: Longitudinal study of immune response to P. aeruginosa antigens in cystic fibrosis. Infect Immun 1983, 42:197-201.

24. Hancock K, Tsang VCW: Development and optimization of the FAST-ELISA for detecting antibodies to Schistosoma mansoni. J Immunol Methods 1986, 92:167-176.

25. Maddison SE: The present status of serodiagnosis and seroepidemiology of schistosomiasis. Diagn Microbiol Infect Dis 1987, 7:93-105.

26. Proesmans M, Balinska-Mizkiewicz W, Dupont L, Bossuyt X, Verhaegen J, Høiby N, de Boeck K: Evaluating the "Leeds criteria" for Pseudomonas aeruginosa infection in a cystic fibrosis centre. Eur Respir J 2006, 27:937-943

27. Anstead M, Heltshe S, Khan U, Barbieri JT, Langkamp M, Döring G, Dharia S, Gibson RL, Treggiari MM, Lymp J, Rosenfeld M, Ramsey B: Pseudomonas aeruginosa serology and risk for re-isolation in the EPIC trial. J Cyst Fibros 2012, 12 (Suppl 2):147-153.

28. Brett MM, Ghoneim ATM, Littlewood JM: Serum antibodies to Pseudomonas aeruginosa in cystic fibrosis. Arch Dis Child 1986, 61:1114-1120.

29. Johansen HK, Norregaard L, Gotzsche PC, Pressler T, Koch C, Høiby N: Antibody response to Pseudomonas aeruginosa in cystic fibrosis patients: a marker of therapeutic success? A 30-year cohort study of survival in danish of patients after onset of chronic Pseudomonas aeruginosa lung infection. Pediatr Pulmonol 2004, 37:427-432.

30. Ratjen F, Walter H, Haug M, Meisner MC, Grasemann H, Döring G: Diagnostic value of serum antibodies in early Pseudomonas aeruginosa infection in cystic fibrosis patients. Pediatr Pulmonol 2007, 42:349-355.

31. Kappler M, Kraxner A, Reinhardt D, Ganster B, Griese M, Lang T: Diagnostic and prognostic value of serum antibodies against Pseudomonas aeruginosa in cystic fibrosis. Thorax 2006, 61:684-688.

32. Tramper-Standers GA, van der Ent CK, Slieker MG, Terheggen-Lagro SWJ, van Berkhout FT, Kimpen JLL, Wolfs TFW: Diagnostic value of serological 
tests against Pseudomonas aeruginosa in a large cystic fibrosis population. Thorax 2006, 61:689-693.

33. Pedersen S, Espersen F, Høiby N: Diagnosis for chronic Pseudomonas aeruginosa infection in cystic fibrosis by enzinme-linked immunosorbent assay. J Clin Microbiol 1987, 25(Suppl 10):1830-1836.

34. Burns JL, Gibson RL, McNamara S, Yim D, Emerson J, Rosenfeld M, Hiatt P, McCoy K, Castile R, Smith AL, Ramsey BW: Longitudinal assessment of Pseudomonas aeruginosa in young children with cystic fibrosis. I Infect Dis 2001, 183:444-452.

35. Pressler T, Bohmova C, Conway S, Dumcius S, Hjelte L, Høiby N, Kollberg H, Tümmler B, Vavrova V: Chronic Pseudomonas aeruginosa infection definition: EuroCareCF Working Group report. J Cyst Fibros 2011, 10(Suppl 2):S75-S78.

36. Farrell PM, Govan JRW: Pseudomonas serology: confusion, controversy and challenges. Thorax 2006, 61:645-647.

doi:10.1186/s13000-014-0158-z

Cite this article as: Mauch et al:: Assessment of lgG antibodies to

Pseudomonas aeruginosa in patients with cystic fibrosis by an enzyme-

linked immunosorbent assay (ELISA). Diagnostic Pathology 2014 9:158.

\section{Submit your next manuscript to BioMed Central and take full advantage of:}

- Convenient online submission

- Thorough peer review

- No space constraints or color figure charges

- Immediate publication on acceptance

- Inclusion in PubMed, CAS, Scopus and Google Scholar

- Research which is freely available for redistribution 